\title{
Optical Characterization of Cubic and Pseudo-cubic Phase Perovskite Single Crystals Depending on Laser Irradiation Time
}

\author{
Hye Ryung Byun and Mun Seok Jeong* \\ Department of Energy Science, Sungkyunkwan University, Suwon 16419, Republic of Korea
}

Received March 28, 2018; accepted March 30, 2018

\begin{abstract}
Photovoltaic and optoelectronic devices based on hybrid metal halide perovskites $\left(\mathrm{MAPbX}_{3}\right.$; $\mathrm{MA}=$ $\mathrm{CH}_{3} \mathrm{NH}_{3}{ }^{+}, \mathrm{X}=\mathrm{Cl}^{-}, \mathrm{Br}^{-}$, or $\mathrm{I}^{-}$) are rapidly improving in power conversion efficiency. Also, during recent years, perovskite single crystals have emerged as promising materials for high-efficiency photovoltaic and optoelectronic devices because of their low defect density. Here we show that the light soaking effect of mixed halide perovskite $\left(\mathrm{MAPbBr}_{3-\mathrm{x}} \mathrm{I}_{\mathrm{x}}\right)$ single crystals can be explained using photoluminescence, time-resolved photoluminescence, and Raman scattering measurements. Unlike Br-based single crystal, Br/I mixed single crystal show a strong light soaking effect under laser irradiation condition that was related to the existence of multiple phases.
\end{abstract}

Keywords: Perovskite single crystal, Light soaking effect

\section{Introduction}

Recently, hybrid lead halide perovskites have been used as active layers in photovoltaic devices [1-3]. The development of various fabrication processes has drastically increased the light-energy harvesting power conversion efficiency of these devices to $>22 \%[4,5]$. So far, the perovskite optoelectronic devices consist of a thin filmtype perovskite, which has high density of defect sites in the grain boundaries [6-8]. To reduce the defect density, perovskite single-crystal-based devices have been introduced [9-11]. Perovskite single crystals are known to be good photovoltaic materials because they do not possess grain boundaries; however, the fundamental physics governing these materials need to be studied in detail for a clearer understanding.

One of the key issues of perovskite devices is the light soaking effect, which is the rapid change of physical parameters under long-time illumination; this effect is usually observed in organic-inorganic lead halide perovskite materials [12-14] and must be solved to achieve perovskite photovoltaic devices with long-term working stabilities [12].

In this work, we systematically characterized the origin of light soaking effect in mixed halide perovskite $\left(\mathrm{MAPbBr}_{3}\right.$ and $\mathrm{MAPbBr}{ }_{2.5} \mathrm{I}_{0.5}$ ) single crystals with photoluminescence(PL) and Raman scattering. The mixed halide perovskite single crystals were synthesized by using the inverse temperature crystallization (ITC) method. We identified the crystallinity

*Corresponding author

E-mail: mjeong@skku.edu of the perovskite crystals by using X-ray diffraction (XRD) measurement. The XRD data of the mixed $\mathrm{Br} / \mathrm{I}$ perovskite single crystals were located at lower degrees than those of cubic phase perovskite $\left(\mathrm{MAPbBr}_{3}\right)$ above $236.9 \mathrm{~K}$. In particular, the $\mathrm{MAPbBr}_{2.5} \mathrm{I}_{0.5}$ single crystal showed a much stronger light soaking effect compare to the cubic phase perovskite $\left(\mathrm{MAPbBr}_{3}\right)$.

\section{Experimental}

\section{Chemicals and solvents}

We used MABr and MAI made by Dyesol Limited. Also, Lead bromide ( $\geq 98 \%)$, N,N-dimethylformamide (DMF, anhydrous, 99.8\%), and $\gamma$-butyrolactone (GBL, $\geq 99 \%$ ) (Sigma-Aldrich) were used. Lead iodide $(\geq 99.99 \%$ ) made by Xi' an Polymer Light Technology Corp. was used for the experiment. All solvents were used as received without any further purification.

\section{Growth of $\mathrm{CH}_{3} \mathrm{NH}_{3} \mathrm{PbBr}_{3-\mathrm{x}} \mathrm{I}_{\mathrm{x}}$ single crystals}

As solvents, DMF and GBL were chosen for $\mathrm{MAPbBr}_{3}$ and $\mathrm{MAPbI}_{3}$, respectively. A solution $(1 \mathrm{M})$ of $\mathrm{PbX}_{2}$ and MAX was prepared in DMF or GBL for $\mathrm{X}=\mathrm{Br}^{-}$and $\mathrm{I}^{-}$, respectively. All solutions were prepared at room temperature, under ambient conditions, and at a humidity of $35 \%-40 \%$. The solutions were filtered using a hydrophobic PTFE-D filter with a pore size of $0.2 \mu \mathrm{m}$. The filtrate $(1.5 \mathrm{~mL})$ was placed in a vial, and the vial was kept in an oven at $80 \mathrm{C}^{\circ}$ to obtain $\mathrm{Br} /$ I-based mixed perovskites $\left(\mathrm{MAPbBr}_{3.0}: \mathrm{MAPbI}_{3.0}=5: 1(\mathrm{v} /\right.$ v)). The single crystals used for measurement were grown over about $3 \mathrm{~h}$. 


\section{Characterization}

PL and Raman spectra were obtained using a multifunctional optical microscopy system (NT-MDT). In this measurement, a $405 \mathrm{~nm}$ laser was used as the excitation source for the laser irradiation. Also, a $633 \mathrm{~nm}$ laser was used as the excitation source for the Raman scattering measurements. Laser irradiation measurements were performed under controlled temperature and humidity $\left(24^{\circ} \mathrm{C}, 42 \%\right)$ in a dark room.

\section{Results and Discussion}

Figure 1(a) Schematic the ITC method. The solutions were heated in an oven and kept at a constant temperature of $80^{\circ} \mathrm{C}$ for $\mathrm{Br} / \mathrm{I} 3: 0$ and $\mathrm{Br} / \mathrm{I} 5: 1$ to initiate crystallization. (b)-(c) XRD data of $\mathrm{MAPbBr}_{3}$ and $\mathrm{MAPbBr}_{2.5} \mathrm{I}_{0.5}$ perovskite single crystals, (insets) snapshots of perovskite single crystals

The $\mathrm{MAPbBr}_{3-\mathrm{x}} \mathrm{I}_{\mathrm{x}}$ perovskite single crystals were synthesized by the ITC method [9,15-18]. The detailed perovskite single-crystal synthesis method is depicted in Figure 1a. In previous reports, this method used the characteristic of a retrograde solubility system, an unusual process in which the decrease of solubility occurs in an appropriate solvent [19]; DMF is a suitable retrograde solubility solvent for Br-based perovskites, while GBL is suitable for I-based ones [19]. Subsequently, $\mathrm{MAPbBr}_{3}$ was synthesized using a DMF-based ITC method. For the perovskite single crystals, solutions of $\mathrm{MAPbBr}_{3}$ (DMFbased) and $\mathrm{MAPbI}_{3}$ (GBL-based) in different volume ratios, $\mathrm{MAPbBr}_{3}: \mathrm{MAPbI}_{3}=5: 1(\mathrm{v} / \mathrm{v})$, were prepared in a vial. And then, the vials were kept in an oven at $80^{\circ} \mathrm{C}$ to obtain single crystal of perovskite (see Experimental section for details).

To confirm the crystallinity of the $\mathrm{MAPbBr}_{3-\mathrm{x}} \mathrm{I}_{\mathrm{x}}$ single crystals, we performed XRD analysis at room temperature (Figure 1b, c). As shown in Figure 1b, XRD patterns of the single crystals demonstrated a pure perovskite phase for $\mathrm{Br} / \mathrm{I}$ 3:0 with a cubic phase at room temperature, which was similar with previous results [15]. Also, the XRD patterns of the $\mathrm{Br} / \mathrm{I} 5: 1$ perovskite single crystals were located at slightly lower degrees than those of $\mathrm{Br} / \mathrm{I}$ 3:0, as observed in Figure 1c. In these results, $\mathrm{Br} / \mathrm{I}$ 3:0 showed a pure phase and the mixed halide perovskite single crystals (Br/I 5:1) showed a pseudo-cubic phase. The insets of Figure $1 \mathrm{~b}$ and $\mathrm{c}$ show the snapshots of the perovskite single crystals; the crystal size was about $3 \mathrm{~mm}$.

Figure 2. PL spectra of perovskite single crystals with different laser irradiation time. (a) and (b) PL spectra of pure and pseudo-cubic phase perovskite single crystals, respectively.

Figure 2 shows the PL spectra of the cubic and pseudo-

a

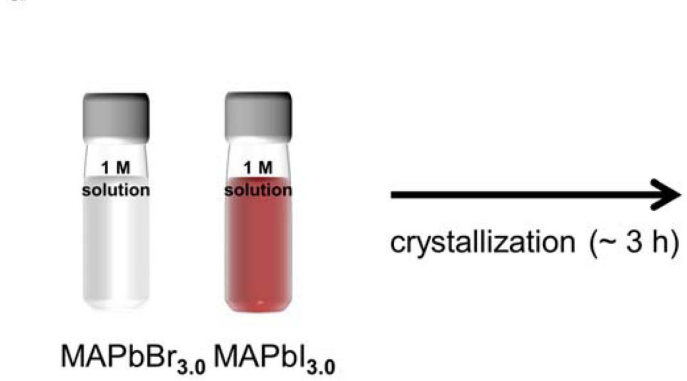

b

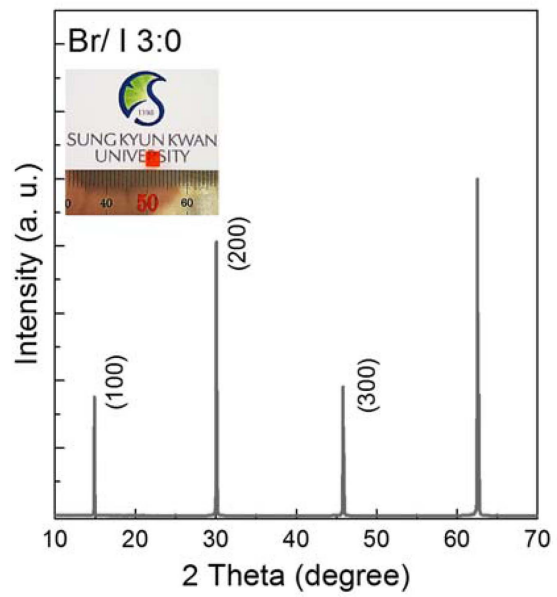

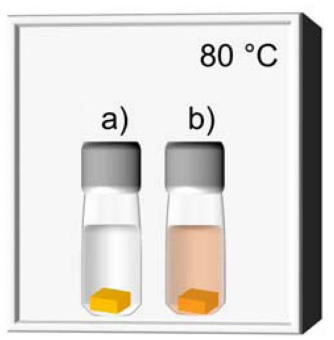

a) $\mathrm{Br} / \mathrm{l} 3: 0$

C

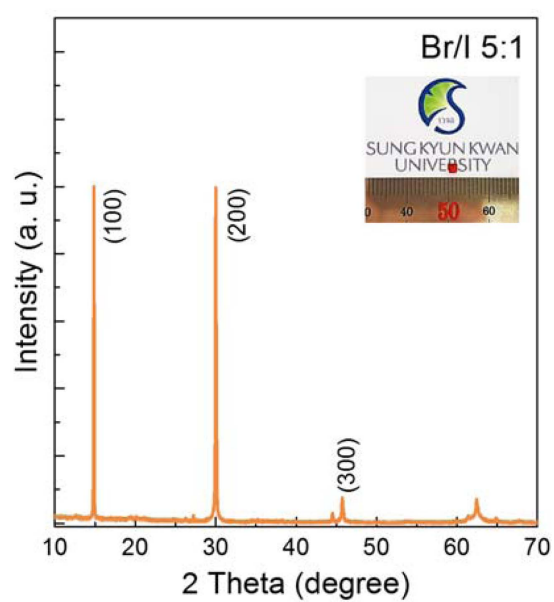

Figure 1. (a) Schematic the ITC method. The solutions were heated in an oven and kept at a constant temperature of $80^{\circ} \mathrm{C}$ for $\mathrm{Br} /$ I 3:0 and $\mathrm{Br} / \mathrm{I}$ 5:1 to initiate crystallization. (b)-(c) XRD data of $\mathrm{MAPbBr}_{3}$ and $\mathrm{MAPbBr}_{2.5} \mathrm{I}_{0.5}$ perovskite single crystals, (insets) snapshots of perovskite single crystals. 

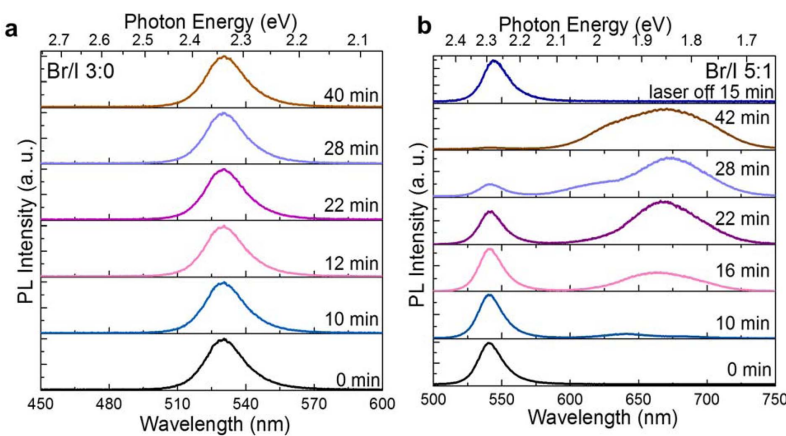

Figure 2. PL spectra of perovskite single crystals with different laser irradiation time. (a) and (b) PL spectra of pure and pseudo-cubic phase perovskite single crystals, respectively. a

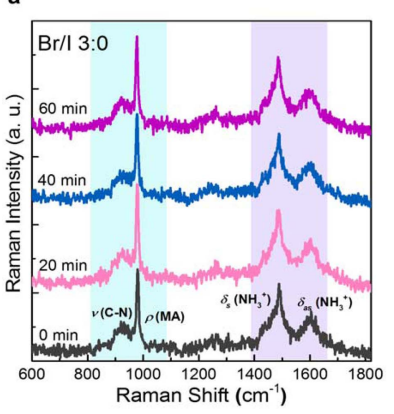

b

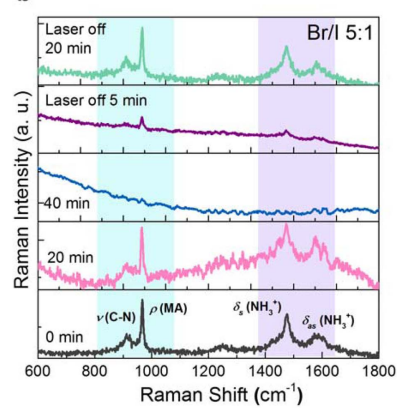

Figure 3. Raman spectra using an excitation wavelength of $633 \mathrm{~nm}$ for (a) cubic (Br/I 3:0) and (b) pseudo-cubic (Br/I 5:1) phase single crystals of perovskite.

cubic phase perovskite single crystals with different laser irradiation time. PL spectra were taken at room temperature with the $405 \mathrm{~nm}$ wavelength excitation laser. During laser irradiation, the PL spectra of the pure phase perovskite single crystals had a band-edge peak, as shown in Figure 2a (no light soaking effect). In contrast, on increasing the laser irradiation time, the band-edge peak of the pseudocubic phase perovskite single crystals gradually disappeared, while new peaks appeared at longer wavelength region. Also, after dark conditions for $15 \mathrm{~min}$ (laser off state), the PL spectra reverted to their initial state, indicating that these changes were fully reversible, as observed in Figure $2 \mathrm{~b}$. This light soaking effect has recently been studied for $\mathrm{MAPbBr}_{3-\mathrm{x}} \mathrm{I}_{\mathrm{x}}$ perovskite thin films and is ascribed to the coexistence of cubic and tetragonal phases [20,21]. Because $\mathrm{MAPbI}_{3}$ exhibits a tetragonal phase at room temperature, the pseudo-cubic phase single crystals contained multiple phases, resulting in the occurrence of the light soaking effect.

During laser irradiation, the Raman spectra of the perovskite single crystals, as shown in Figure 3, were obtained at an excitation wavelength of $633 \mathrm{~nm}$ with a spectral range from 600 to $1800 \mathrm{~cm}^{-1}$. The Raman scattering analysis focused on the $\mathrm{C}-\mathrm{N}$ stretching vibration mode around $980 \mathrm{~cm}^{-1}$ and $\mathrm{NH}_{3}$ symmetric bending mode around $1500 \mathrm{~cm}^{-1}$. Similar to the PL results, the Raman spectra of the cubic phase perovskite single crystals were nearly unchanged with increasing laser irradiation time, whereas the Raman peaks of the pseudo-cubic phase perovskite single crystals disappeared for laser irradiation times greater than $20 \mathrm{~min}$. Under dark conditions, the Raman peaks observed initially re-appeared. From the broad PL data around $700 \mathrm{~nm}$ in Figure 2(b), we found that that the $633 \mathrm{~nm}$ laser used for Raman scattering excited the $\mathrm{PL}$ as well. Consequently, after $20 \mathrm{~min}$ irradiation, Raman scattering was overwhelmed by PL. Therefore, we could not observe the Raman scattering signals for irradiation times greater than $20 \mathrm{~min}$. Recently, our group reported the XRD measurements of $\mathrm{MAPbBr} 3-\mathrm{I} \mathrm{I}_{\mathrm{x}}$ perovskite single crystals depending on illumination, which led to structural changes in the pseudo-cubic phase perovskite single crystals due to the light soaking effect, and these changes were reverted under dark conditions [22]. Generally, Raman vibration modes are closely related to the structure of materials, so we supposed that the Raman shifts in the pseudo-cubic phase perovskite single crystals were attributed to structural changes due to laser irradiation.

\section{Summary}

We demonstrated the laser irradiation time-dependent optical properties of $\mathrm{MAPbBr}_{3-\mathrm{x}} \mathrm{I}_{\mathrm{x}}$ perovskite single crystals. By PL and Raman scattering measurements, we showed that, the pseudo-cubic phase perovskite single crystals exhibited the light soaking effect with increasing laser irradiation time, whereas cubic phase single crystal of perovskite remained unchanged. Also, the light soaking effect was attributed to the coexistence of cubic and tetragonal phases and was fully reversible after some time under dark conditions. These findings provide an understanding of the fundamental properties of hybrid perovskite materials.

\section{Acknowledgements}

This study was supported by the Basic Science Research Program through the National Research Foundation of Korea (NRF) funded by the Ministry of Education (NRF2016R1A6A3A11936024).

\section{References}

[1] M. A. Green, A. Ho-Baillie, and H. J. Snaith, Nat. Photon. 8, 506514 (2014).

[2] M. B. Johnston and L. M. Herz, Acc. Chem. Res. 49, 146-154 (2016).

[3] N. G. Park, M. Grätzel, and T Miyasaka, Organic-Inorganic Halide Perovskite Photovoltaics: From Fundamentals To Device Architectures (Springer International Publishing, Switzerland, 2016), pp. 1-17.

[4] NREL Research Cell Record Efficiency Chart. https://www.nrel. gov/pv/assets/images/efficiency-chart.png (Accessed on 18 July 2017).

[5] M. A. Green, K. emery, Y. Hishikawa, W. Warta, E. D. Dunlop, D. H. Levi, and A. Ho-Baillie, Prog. Photo. Res. Appl. 25, 3-13 (2017).

[6] Y. H. Shao, Z. G. Xiao, C. Bi, Y. B. Yuan, and J. S. Huang, Nat. 
Commun. 5, 5784 (2014).

[7] Q. Wang, Y. C. Shao, Q. F. Dong, Z. G. Xiao, Y. B. Yuan, and J. S. Huang, Energy Environ. Sci. 7, 2359-2365 (2014).

[8] Z. T. Wu, Z. Z. Luo, Y. T. Shen, W. W. Zhao, W. H. Wang, H. Y. Nan, X. T. Guo, L. T. Sun, X. R. Wang, Y. M. You, and Z. H. Ni, Nano Res. 9, 3622-3631 (2016).

[9] Q. F. Dong, Y. J. Fang, Y. C. Shao, P. Mulligan, J. Qiu, L. Cao, and J. S. Huang, Science, 347, 967-970 (2015).

[10] M. I. Saidaminov, A. L. Abdelhady, B. Murali, E. Alarousu, V. M. Burlakov, W. Peng, I. Dursun, L. F. Wang, Y. He, G. Maculan, A Goriely, T. Wu, O. F. Mohammed, and O. M. Bakr, Nat. Commun. 6, $7586(2015)$.

[11] Y. J. Fang, Q. F. Dong, Y. C. Shao, Y. B. Yuan, and J. S. Huang, Nat. Photonics, 9, 679 (2015).

[12] C. Zhao, B. B. Chen, X. F. Qiao, L. Luan, K. Lu, and B. Hu, Adv. Energy. Mater. 5, 150029 (2015).

[13] S. J. Yoon, S. Draguta, J. S. Manser, O. Sharia, W. F. Schneider, M. Kuno, and P. V. Kamat, Acs. Energy. Lett. 1, 290-296 (2016).

[14] R. Gottesman, L. Gouda, B. S. Kalanoor, E. Haltzi, S. Tirosh, E. Rosh-Hodesh, Y. Tischler, A. Zaban, C. Quarti, E. Mosconi, and F. J. De Angelis, Phys. Chem. Lett. 6, 2332-2338 (2015).

[15] D. Shi, V. Adinolfi, R. Comin, M. J. Yuan, E. Alarousu, A. Buin, Y.
Chen, S. Hoogland, A. Rothenberger, K. Katsiev, Y. Losovyj, X. Zhang, P. A. Dowben, O. F. Mohammed, E. H. sargent, and O. M. Bakr, Science, 347, 519-522 (2015).

[16] C. C. Stoumpos, C. D. Malliakas, and M. G. Kanatzidis, Inorg. Chem. 52, 9019-9038 (2013).

[17] Y. Y. Dang, Y. Liu, Y. X. Sun, D. S. Yuan, X. L. Liu, W. Q. Lu, G. F. Liu, H. B. Xia, and X. T. Tao, Cryst. Eng. Comm. 17, 665-670 (2015).

[18] T. Baikie, Y. N. Fang, J. M Kadro, M. Schreyer, F. X. Wei, S. G. Mhaisalkar, M. Graetzel, and T. J. White, J. Mater. Chem. A, 1, 5628-5641 (2013).

[19] M. I. Saidaminov, A. L. Abdelhady, G. Maculan, and O. M. Bakr, Chem. Commun. 51, 17658-17661 (2015).

[20] A. Sadhanala, F. Deschler, T. H. Thomas, S. E. Dutton, K. C. Goedel, F. C. Hanusch, M. L. Lai, U. steiner, T. Bein, P. Docampo, D. Cahen, and R. H. Friend, J. Phys. Chem. Lett. 5, 2501-2505 (2014).

[21] P. U. Jepsen, W. Schairer, I. H. Libon, U. Lemmer, N. E. Hecker, M. Birkholz, K. Lips, and M. Schall, Appl. Phys. Lett. 79, 1291$1293(2001)$

[22] H. R. Byun, D. Y. Park, H. M. Oh, G. Namkoong, and M. S. Jeong, ACS Photonics, 4, 2813-2820 (2017). 